\title{
Prestando muita atenção no YouTube
}

\author{
Resenha do livro Youtube e a revolução digital: Como o maior \\ fenômeno da cultura participativa está transformando a mídia e a \\ sociedade, de Jean Burgess e Joshua Green. Tradução de \\ Ricardo Giassetti. São Paulo: Aleph, 2009.
}

Ariane Holzbach ${ }^{1}$

Apesar de ter apenas cinco anos de existência, a plataforma de veiculação de vídeos YouTube rapidamente se tornou elemento importante da cultura contemporânea. O site é crucial para observar e compreender importantes questões relacionadas, por exemplo, aos debates sobre a reconfiguração das tecnologias de comunicação na atualidade, sobre copyright e diretos autorais a partir das novas tecnologias, sobre a reconfiguração da indústria fonográfica, sobre o papel do videoclipe na cultura contemporânea e a perda de seu status exclusivamente televisivo, sobre a maior participação da audiência no processo de criação de conteúdo midiático e sobre a popularização de novos fenômenos sociais, como os vídeos virais e os flashmobs. Contudo, é surpreendente constatar que, em especial no Brasil, ainda são escassos os trabalhos acadêmicos que de fato se debruçam sobre a plataforma transformando-a em protagonista. Nesse sentido, Jean Burgess e Joshua Green preenchem parte dessa lacuna com o livro "Youtube e a revolução digital: Como o maior fenômeno da cultura participativa está transformando a mídia e a sociedade”, lançado no Brasil poucos meses depois da publicação de sua versão original em inglês.

Jean Burgess é pesquisadora sênior do Creative Industries Faculty, pertencente à Queensland University of Technology, enquanto Joshua Green é coordenador do projeto criado por Henry Jenkins, o Convergence Culture Consortium (C3), uma instituição que visa a mediar relações entre a pesquisa acadêmica e a indústria da mídia. Essa proximidade com o autor de Cultura da Convergência, uma das referências mais presentes atualmente nos estudos

\footnotetext{
${ }^{1}$ Mestre e doutoranda do Programa de Pós-graduação em Comunicação da Universidade Federal Fluminense. Formada em jornalismo pela UFPE. Atualmente é professora da Universidade Gama Filho e Professora Substituta da Universidade do Estado do Rio de Janeiro. E-mail: aridiniz@gmail.com
} 
relacionados às novas tecnologias, fez com que o livro olhasse para o YouTube não apenas como uma plataforma de veiculação audiovisual, mas a partir da perspectiva da cultura participativa. Além disso, o livro analisa o modelo de negócios desenvolvido na plataforma, narra detalhadamente a história de surgimento do site e conta interessantes casos de pessoas comuns que através de seus canais, comentários, vídeos amadores e vlogs estão inseridas em uma imensa e complexa rede social que tem a sua própria lógica, chamada pelos autores de "Youtubidade".

A obra se divide em seis capítulos que tratam de seis características que os autores consideram centrais para compreender o papel do YouTube no mundo contemporâneo: a forma e o motivo para o qual ele foi criado, a sua relação com as mídias de massa, a popularidade alcançada pela plataforma, a rede social criada dentro do YouTube, o modelo de negócios do site e, por fim, uma reflexão sobre o que esperar do futuro da plataforma. Além disso, o final do livro traz um artigo de Henry Jenkins sobre as necessidades sociais que levaram ao aparecimento do YouTube e um artigo de John Hartley sobre as possibilidades existentes no YouTube para minimizar o analfabetismo digital. Todas essas perspectivas são contempladas em pouco mais de 200 páginas, o que faz com que não se tenha uma exaustiva análise de cada item apontado pelos autores. Trata-se mais de expor a pluralidade de usos e possibilidades da plataforma do que de analisar profundamente cada um dos itens citados.

O primeiro capítulo, "A importância do YouTube", narra historicamente o surgimento do site e traz o argumento central do livro: a sua principal característica é ser uma enorme rede social que tensiona a relação entre a mídia institucionalizada - as grandes empresas que de alguma forma utilizam o site - e o usuário "comum". Os autores lembram que quando o site entrou no ar, ele não foi uma ideia original, visto que havia outras plataformas de divulgação online de audiovisual, e nem tinha como função servir às instituições midiáticas. Trata-se, pois, de um exemplo de mídia que teve seu uso modificado pelas necessidades sociais. Os criadores do site - Chad Hurley, Steve Chen e Jawed Karim - colocaram o material no ar em junho de 2005 com o objetivo de "eliminar as barreiras técnicas para maior compartilhamento de vídeos na internet" (pg. 17), ou seja, possibilitar ao usuário comum um ambiente simples com ferramentas intuitivas que facilitassem a veiculação de material e, especialmente, a troca de informações e conteúdos entre usuários. Prova disso é o primeiro slogan do site: Your Digital Video Repository (Seu Repositório de Vídeos Digitais”), que explicita o uso do espaço como uma biblioteca de material audiovisual ${ }^{2}$.

\footnotetext{
${ }^{2}$ A ideia do YouTube utilizado como um grande arquivo de audiovisual foi aprofunda por Robert Gehl (2009), que trata do assunto sob a perspectiva da democratização na internet.
} 
O capítulo seguinte, "O YouTube e a mídia de massa", se preocupa em observar que tipo de imagem os meios de comunicação de massa constroem em torno do YouTube. Os autores analisam que em pouco mais de dois anos o discurso da imprensa mudou bastante em relação ao site. Segundo os autores, o YouTube era visto inicialmente como um repositório mundial de conteúdo heterogêneo que era "mal administrado, de comportamentos criminosos, antiéticos e patológicos dedicados à juventude como categoria de risco" (pg. 37), embora a característica de servir como um ambiente para expressão individual fosse sempre reforçada pela mídia. Os autores creditam a imagem negativa transmitida pelos meios de comunicação de massa a um "pânico midiático" que ronda as tecnologias de comunicação sempre que algo novo no campo midiático surge. Esse pânico seria reflexo dos "sintomas do desconforto e a incerteza que cercam o campo de atuação da mídia e a autoridade moral, provocados pelo uso em massa das novas tecnologias de mídia para publicação autônoma” (pg. 40). Com a crescente popularização do site e a sua consequente apropriação por diversas instituições midiáticas, a mídia passou a ver o YouTube como um legítimo meio de comunicação de massa. Questões que permeiam as mídias "tradicionais", como a cultura das celebridades, e questões que tensionam esses elementos, como os vídeos amadores que transformam usuários da plataforma em celebridades, também são rapidamente são analisados.

"A cultura popular do YouTube" é o terceiro capítulo e procura entender o que torna um vídeo popular no YouTube. Sem problematizar os conceitos sobre "ser popular", os autores descrevem uma experiência feita em 2007 com os 4.320 vídeos mais acessados, mais comentados, mais respondidos e mais adicionados aos favoritos do site, na tentativa de descobrir pistas que expliquem os motivos pelos quais determinados materiais são exaustivamente acessados e atingem recordes de visualizações. Para tanto, os autores analisam, por exemplo, as métricas criadas pelo YouTube para medir a popularidade dos vídeos. Uma das constatações importantes relacionadas a essa questão diz que "por comunicarem à audiência o que é contabilizado como popular no YouTube, essas métricas também tem um papel ativo na criação da realidade do que é popular no YouTube: elas não são meramente descritivas, mas também performáticas" (pg. 64). O resultado da pesquisa mostra que cerca de metade desses vídeos foi postada por usuários comuns, sendo que desse montante, cerca de $40 \%$ eram vlogs (variante dos blogs cujo conteúdo é criado a partir de vídeos), explicitando o impacto dos usuários “comuns" no YouTube. 
O quarto capítulo, "A rede social do YouTube", trata do site sob uma perspectiva pouco usual, priorizando não os conteúdos veiculados no ambiente, e sim os usos feitos desse conteúdo pelos usuários no interior da plataforma. Os autores observam que embora o YouTube tenha sido criado para compartilhamento de conteúdo, o site não oferece recursos que priorizem a relação entre os diversos usuários: "apesar da sua retórica comunitária, a arquitetura e o design do YouTube convidam mais à participação individual do que à atividade coletiva" (pg. 93). Essa característica não impediu, contudo, que os próprios usuários criassem maneiras de manter uma relação intensa no interior da plataforma. Uma dessas maneiras são os vlogs que, como ocorre com os blogs, se constroem com base na relação entre o autor e seus leitores. A estrutura dos vlogs incentiva os comentários, o compartilhamento de informações e a troca de conteúdos que não raro ocorre em tempo real, o que transforma o YouTube em uma grande rede social. Afora isso, o capítulo descreve uma série de soluções encontradas pelos usuários para suprir a necessidade de uma maior socialização de conteúdo, como a introdução de comentários e links clicáveis inseridos em vídeos contínuos, recurso que até metade de 2008 não era oferecido no site, e os vídeos "meta-YouTube" que, entre outras funções, são criados pelos usuários para evocar a necessidade de comunicação entre "YouTubers". O "sucesso" atingido por um vídeo, de acordo com os autores, muitas vezes tem relação com o uso eficiente desses recursos.

Depois de tratar de questões relacionadas à sociabilidade entre usuários do site, o quinto capítulo enfoca a perspectiva da cidadania e como ela pode ser expressa através da plataforma. O capítulo intitula-se "A política cultural do YouTube" e desenvolve o argumento de que mesmo o site sendo um empreendimento comercial, ele serve também como um viabilizador de participação cultural dos cidadãos: "o YouTube é um site potencial para a cidadania cultural cosmopolita - um espaço na qual indivíduos podem representar suas identidades e perspectivas, envolver-se com as representações pessoais de outros e encontrar diferenças culturais" (pg. 112). O capítulo narra alguns casos interessantes de situações em que o usuário utiliza o YouTube como espaço de protesto, e muitas vezes esse protesto recai sobre os próprios gerenciadores do site. Isso ocorreu, por exemplo, em 2007, quando o YouTube implementou várias versões localizadas do site, com páginas personalizadas para países como Brasil, México, Holanda, Rússia e diversos outros. Alguns "YouTubers" falantes de inglês que não eram do Reino Unido ou dos Estados Unidos, como australianos e canadenses, fizeram vídeos reclamando que o YouTube não havia feito uma versão para eles e exigiam uma versão local do site. Além disso, o capítulo menciona a existência de filtros de 
conteúdo supostamente impostos por corporações e governos nacionais, embora não se aprofunde nem problematize muito a questão.

O sexto e último capítulo escrito pela dupla de autores, "Os caminhos incertos do YouTube", traz uma reflexão inicial sobre o futuro do site, tendo em vista o poder da cultura participativa e os variados usos que ela desenvolveu no YouTube. Um dos maiores desafios do site, segundo os autores, será manter o seu crescimento sustentável, ou seja, encontrar um equilíbrio entre a busca por um crescimento regular, que mantenha o site em um lugar estratégico de veiculação de mídia institucionalizada e de usuários "comuns", e, ao mesmo tempo, que mantenha a heterogeneidade cultural e estética do que é veiculado ali.

O penúltimo capítulo do livro traz o artigo de Henry Jenkins, "O que aconteceu antes do YouTube?". O texto notoriamente segue as reflexões de Raymond Williams (1990) ao tentar mostrar a necessidade social que estava patente no mundo antes do nascimento do site. Jenkins estrutura seu argumento da mesma forma que Williams fez ao descrever as origens sociais que deram condições para o surgimento da televisão no início do século $\mathrm{XX}$. Inicialmente o autor afirma que da maneira como se olha para o YouTube, cria-se a ideia de que o site surgiu "da noite para o dia", e que é preciso compreender o desenvolvimento da cultura participativa contemporânea para entender os elementos culturais que deram impulso para o surgimento e popularização do site. Jenkins argumenta que o YouTube "não somente mudou as condições de produção como também alterou os contextos de circulação e recepção" (pg. 149), mas que para isso ocorrer foi preciso, por exemplo, que houvesse o desenvolvimento anterior de uma cultura de produção de conteúdo feita por usuários "comuns" que se aproveitaram da tecnologia como meio de expressar e divulgar informações de seu interesse. Como fez em Cultura da Convergência, neste artigo Jenkins reforça o papel do fã como produtor e modificador de conteúdo midiático, inclusive descrevendo casos, e também reflete sobre a relação cada vez mais convergente dos conteúdos criados e das mídias que veiculam esse conteúdo.

Por fim, o último capítulo do livro traz uma reflexão de John Hartley, professor da Queensland University of Technology e bastante interessado em cultura popular e democratização da informação que percebe o YouTube como como um ambiente propício para otimizar a alfabetização digital. Intitulado "Utilidades do YouTube: alfabetização digital e a expansão do conhecimento", o capítulo retrata uma importante contradição: se por um lado os jovens contemporâneos consideram o computador e seu conteúdo parte integrante de suas vida, por outro as escolas onde esses jovens adquirem boa parte do conhecimento não utilizam as possibilidades do computador de forma adequada para aproveitar a naturalização 
da tecnologia feita pelos jovens. De acordo com Hartley, "o sistema de ensino respondeu à era digital com a proibição de acesso aos ambientes digitais nas escolas, inclusive ao YouTube, à exceção de alguns 'jardins suspensos' sob rígido controle dos professores” (pg. 170). Essa limitação do sistema educacional incentivou o surgimento de uma forma de entretenimento baseada na expressão corporal e criativa desses jovens ávidos por se comunicar. O autor explicita um olhar sobre o YouTube que oferece um contraponto em relação às tecnologias da comunicação solidificadas no século XX. Ele afirma, por exemplo, que um dos usos feitos do YouTube transgride a narrativa consolidada na televisão, no rádio e no cinema e oferece conteúdos sem "histórias no sentido tradicional da palavra" (pg. 173).

Analisando o livro como um todo, é verdade que, como analisa Erick Felinto (2010), o título da obra - Youtube e a revolução digital: Como o maior fenômeno da cultura participativa está transformando a mídia e a sociedade - parece deixar patente um tratamento da cibercultura e dos fenômenos tecnológicos contemporâneos a partir de uma perspectiva de apagamento histórico. Tratar o YouTube como uma plataforma "revolucionária" e como "o maior fenômeno da cultura participativa" causam, nas palavras de Felinto (2010, pg. 2), "uma sensação de maravilhamento tecnológico, entusiasmo infantil e desprezo por tudo aquilo que é "antigo" que em nada auxilia a compreensão desses fenômenos e sua relação com a continuidade histórica. Se a observação é legítima, ao menos é interessante observar que os autores fazem um esforço no sentido de compreender o YouTube como um fenômeno inserido em uma cultura mais ampla, baseada no argumento de que a cultura participativa pode não ser recente, mas tem passado por um processo de intensificação sem precedentes a partir das possibilidades criadas com as novas tecnologias. O surgimento do YouTube e seu uso feito pelas instituições e pelo público são reflexos dessa intensificação.

Além disso, a variedade de elementos relacionados ao YouTube destacados no livro embora não aprofundados - fazem com que se preste mais atenção ao fato de que a plataforma é muito mais do que um imenso repositório de conteúdo audiovisual. Na verdade, para os autores, essa sua função nem estaria entre as mais importantes do site.

\section{Referências bibliográficas}

BURGUESS, Jean, GREEN, Joshua. YouTube e a Revolução Digital: como o maior fenômeno da cultura participativa está transformando a mídia e a sociedade. São Paulo: Aleph, 2009. 
FELINTO, Erick. Em Busca do Tempo Perdido: O Sequestro da História na Cibercultura e os Desafios da Teoria da Mídia. Trabalho apresentado no GT "Comunicação e Cibercultura" do XIX Encontro da Compós, PUC-RJ, 2010.

GEHL, Robert. YouTube as archive: Who will curate this digital Wunderkammer? International Journal of Cultural Studies. Vol. 12. 2009.

JENKINS, Henry. Cultura da Convergência. São Paulo: Aleph, 2009.

WILLIAMS, Raymond. The technology and the society. In: Television: technology and cultural form. London: Routledege, 1990. 